Résumés des conférences et travaux

\title{
Emblématique occidentale
}

\section{Laurent Hablot}

\section{(2) OpenEdition Journals}

Édition électronique

URL : https://journals.openedition.org/ashp/4515

DOI : $10.4000 /$ ashp.4515

ISSN : 1969-6310

Éditeur

Publications de l'École Pratique des Hautes Études

Édition imprimée

Date de publication : 1 septembre 2021

Pagination : 309

ISSN : 0766-0677

Référence électronique

Laurent Hablot, «Emblématique occidentale », Annuaire de l'École pratique des hautes études (EPHE),

Section des sciences historiques et philologiques [En ligne], 152 | 2021, mis en ligne le 14 juin 2021, consulté le 20 juin 2022. URL : http://journals.openedition.org/ashp/4515 ; DOI : https://doi.org/ 10.4000/ashp.4515 


\title{
EMBLÉMATIQUE OCCIDENTALE
}

\author{
Directeur d'études : M. Laurent HABLOT
}

Programme de l'année 2019-2020 : Dossiers d'héraldique et d'emblématique.

Les enseignements de cette année universitaire ont été répartis entre deux modules : les conférences doctorales; les conférences de master.

L'année 2019 s'est ouverte sur le thème des broderies héraldiques, en lien avec l'exposition L'Art en broderie au Moyen Âge du musée de Cluny. Après une conférence introductive centrée sur les bourses armoriées médiévales (14 novembre 2019), les auditeurs ont pu bénéficier d'une visite privée de l'exposition (15 novembre 2019) mettant en valeur les nombreuses pièces armoriées. La séance du 28 novembre a été consacrée à l'emblématique de Charles VII en lien avec l'exposition et les journées d'études programmés à Troyes autour du traité de 1420 (reportées à décembre 2021). Après la participation de la conférence au colloque sur la Broderie au Moyen Âge (13 et 14 janvier 2020) à l'INHA, les auditeurs ont entendu l'équipe du volet alsacien de Sigilla, Sigi-Al, présenter un ensemble de dossiers sigillographiques (23 janvier 2020). La conférence de master du 6 février 2020 a été consacrée à l'emblématique des seigneurs de Rais présentée par Yves Airiau et celle du lendemain à l'exposé de dossiers d'héraldique monumentale par Matteo Ferrari (coordinateur Armma) et Paul-François Brouck (responsable du volet breton d'Armma). La séance du 13 février 2020 a accueilli M. Lesbégueris qui présentait ses recherches de master sur les carrosses armoriés. La séance du 12 mars 2020 ouvrait la série d'interventions programmées du professeur invité du séminaire, Torsten Hiltmann, sur le thème de la communication visuelle héraldique (EPHE, INHA, SFHS). La mise en œuvre d'une politique nationale et internationale de confinement a hélas interrompu son séjour et ses conférences ont été reportées sine die.

Les conférences du DE se sont néanmoins poursuivies sous forme virtuelle au moyen de présentations enregistrées téléchargeables, les 26 mars 2020 (Les couteaux $\mathrm{du}$ British Museum aux armes des Jacqueline de Bavière, épouse de Jean de Touraine); 27 mars 2020 (Les sceaux de René d'Anjou), 3 avril 2020 (Les concessions héraldiques des Aragon-Naples), 22 avril 2020 (Pièces orfévrées islamiques aux armes des Lusignan Chypre par Simon Rousselot, doctorant et L'héraldique et les sceaux des Lusignan-Chypre par L. Hablot), 30 avril 2020 (Les témoignages héraldiques de Jouvenel des Ursins par Matteo Ferrari et L. Hablot), 15 mai 2020 (Dossiers : le bras reliquaire de saint Judicaël et le décor héraldique de l'église de Brindisi); 8 juin 2020 (Dossiers : le mécénat héraldique de la famille de Bar [Bourges et Rocamadour]). 